\title{
Avaliação da biocompatibilidade de implantes mamários de silicone esterilizados por calor seco e pelo óxido de etileno
}

\author{
Janice Campos de Azevedo ${ }^{1}$, Áurea Silveira Cruz ${ }^{2}$, Terezinha de Jesus Andreoli Pinto ${ }^{*}$ \\ 1 Departamento de Farmácia da Faculdade de Ciências Farmacêuticas da \\ Universidade de São Paulo, ${ }^{2}$ Instituto Adolfo Lutz
}

*Correspondência:

T. J. A. Pinto

Departamento de Farmácia

Faculdade de Ciências Farmacêuticas

da Universidade de São Paulo

Av. Prof. Lineu Prestes, 580 Bloco 15

05508-900 - São PAulo, SP - Brasil

E-mail: tjapinto@usp.br
Os implantes mamários de silicone têm sido empregados, tanto nas cirurgias de aumento de mama, quanto na reconstrução do tecido mamário. A segurança biológica deste tipo de implante deve ser garantida, pois, em função da esterilização estes materiais, podem sofrer alterações oriundas dos processos esterilizantes por comprometimento da estrutura química dos polímeros. O objetivo deste trabalho consistiu na avaliação da biocompatibilidade de implantes mamários preenchidos com gel de silicone, de superfície lisa e texturizada submetidos à esterilização por calor seco e óxido de etileno. Empregou-se, para tanto, método in vitro, avaliando a citotoxicidade pelo método de captura do vermelho neutro, utilizando a linhagem celular NCTC clone 929. Os resultados obtidos demonstraram não haver comprometimento da biocompatibilidade dos biomateriais submetidos aos dois processos (calor seco e óxido de etileno), assim como comprovaram a eficácia de ambos na esterilização dos implantes.

\section{INTRODUÇÃO}

Os tecidos e órgãos do corpo humano estão sujeitos a doenças e injúrias, que, se não tratadas, podem levar à dor, restrição dos movimentos e perda da função. Em muitos casos o tratamento envolve a remoção do tecido ou órgão afetado e sua substituição por um enxerto de tecido vivo ou um análogo artificial - um biomaterial (Williams, 1985). O termo biomaterial refere-se a um material natural ou sintético destinado a interagir com sistemas biológicos para avaliar, tratar, aumentar ou substituir um órgão, tecido ou função do organismo (Williams, 1999).

Dentre os diversos biomateriais poliméricos disponíveis, o silicone tem sido empregado como substituinte de tecidos moles e cartilagens (Seal, Otero, Panitch, 2001). Por ser resultante da polimerização do dimetilsiloxano, o silicone pode se apresentar nas formas físicas: fluida, gel e elastomérica, decorrentes do comprimento e ramificações da cadeia do polímero.

A mama é um dos inúmeros tecidos e estruturas que podem ser substituídos por próteses de silicone em cirurgias de aumento ou de reconstrução mamária após mastectomia. Quando as próteses são implantadas, devese garantir a condição de esterilidade das mesmas. Dentre os métodos de esterilização empregados, o calor seco, por fazer uso de temperaturas elevadas, pode promover a hidrólise e/ou fusão da matriz do polímero, comprometendo a biocompatibilidade dos implantes. A esterilização 
química gasosa por óxido de etileno tem como vantagem propiciar tratamento eficaz a temperaturas relativamente baixas, porém os resíduos do gás, por serem agentes alquilantes, podem reagir com grupos funcionais do polímero provocando alterações das propriedades do silicone, comprometendo o biomaterial. O objetivo deste estudo foi avaliar a biocompatibilidade de implantes mamários de silicone após terem sido submetidos aos processos de esterilização. Para esta avaliação foi empregado método in vitro de avaliação da citotoxicidade dos materiais, através da técnica de cultura de célula empregando o corante vital vermelho neutro.

\section{MATERIAL E MÉTODOS}

\section{Amostras}

Foram analisados dois modelos de próteses mamárias, obtidas junto a produtor nacional, constituindo-se os implantes de invólucros de silicone elastomérico vulcanizado, de superfície lisa e de superfície texturizada, ambos cheios com silicone na forma de gel, com volumes de $220 \mathrm{~mL}$.

\section{Métodos}

\section{Esterilização dos implantes mamários}

A biocarga inicial dos implantes não-esterilizados foi determinada pela contagem microbiana empregando método de filtração por membrana (USP, 2004). Após a determinação quantitativa (Tabela I) e qualitativa (Tabela II) da biocarga dos implantes, procedeu-se à esterilização por calor seco $\left(121^{\circ} \mathrm{C}\right.$, por 32 horas) de 110 unidades não esterilizadas de cada modelo de prótese mamária. Para a esterilização por óxido de etileno $\left(48{ }^{\circ} \mathrm{C} / 55 \%\right.$ $\mathrm{UR} / 300 \mathrm{~min} / 750 \mathrm{mg} / \mathrm{L}$ ), também foram empregadas 110 unidades de cada tipo de implante, sendo os parâmetros definidos de acordo com orientação da ISO 11135:1994.

\section{Comprovação da esterilidade}

O teste de esterilidade foi realizado por método direto (USP, 2004), empregando 100 unidades de cada tipo de implante submetidas aos diferentes processos de esterilização. Os implantes foram cortados, empregando tesouras estéreis e os fragmentos obtidos foram transferidos para tubos de ensaio contendo cerca de $80 \mathrm{~mL}$ de meios de cultura. Foram empregados o caldo tioglicolato $\left(\right.$ Oxoid $\left.^{\circledR}\right)$, para detecção de bactérias aeróbias e anaeróbias e caldo caseína de soja $\left(\mathrm{Oxoid}^{\circledR}\right)$, para
TABELA I - Biocarga dos implantes de silicone não esterilizados

\begin{tabular}{|c|c|c|}
\hline \multirow[t]{2}{*}{ Amostra } & \multicolumn{2}{|c|}{ Implante de silicone } \\
\hline & $\begin{array}{l}\text { superfície lisa } \\
\text { (UFC/implante) }\end{array}$ & $\begin{array}{l}\text { superfície texturizada } \\
\text { (UFC/implante) }\end{array}$ \\
\hline 1 & ND & 6 \\
\hline 2 & 2 & ND \\
\hline 3 & ND & 4 \\
\hline 4 & 18 & 27 \\
\hline 5 & ND & 6 \\
\hline 6 & ND & 15 \\
\hline 7 & 6 & 8 \\
\hline 8 & 3 & 2 \\
\hline 9 & 19 & 24 \\
\hline 10 & 17 & 7 \\
\hline 11 & 14 & 42 \\
\hline 12 & 2 & 11 \\
\hline 13 & 3 & 2 \\
\hline 14 & 2 & 14 \\
\hline 15 & ND & 3 \\
\hline 16 & 27 & 6 \\
\hline 17 & ND & 10 \\
\hline 18 & 2 & 6 \\
\hline 19 & 11 & 112 \\
\hline 20 & 26 & ND \\
\hline 21 & ND & 3 \\
\hline 22 & ND & 4 \\
\hline 23 & 2 & ND \\
\hline 24 & 4 & 7 \\
\hline 25 & 2 & 2 \\
\hline 26 & 7 & 4 \\
\hline 27 & 3 & 12 \\
\hline 28 & ND & ND \\
\hline 29 & ND & ND \\
\hline 30 & 11 & 21 \\
\hline
\end{tabular}

UFC: Unidade Formadora de Colônia

ND: Contaminante não detectado

detecção de bolores e leveduras, incubados por 14 dias a $32,5 \pm 2,5^{\circ} \mathrm{C}$ e $22,5 \pm 2,5^{\circ} \mathrm{C}$, respectivamente.

\section{Avaliação da citotoxicidade}

Foi empregada a linhagem celular NCTC clone 929 (ATCC CCL1), sendo a citotoxicidade avaliada pelo método de captura do vermelho neutro (Borenfreund, Puerner, 1985). No procedimento, utilizaram-se extratos obtidos por imersão de fragmentos dos implantes com área de $4 \mathrm{~cm}^{2}$, colocados em meio de Eagle sem soro a $37{ }^{\circ} \mathrm{C}$ 
TABELA II - Microrganismos constituintes da biocarga dos implantes não-esterilizados

\begin{tabular}{lc}
\hline Microrganismo & Fonte Provável \\
\hline Moraxella sp & superfície de mucosa humana \\
Staphylococcus & conduto auditivo humano \\
auricularis & \\
Staphylococcus & microbiota humana \\
saprophyticus & da uretra e reto \\
Micrococcus & microbiota transitória \\
luteus & da pele humana \\
Bacillus cereus & Solo e vegetação \\
Levedura & microbiota normal da orofaringe \\
& e trato gastrointestinal \\
\hline
\end{tabular}

por 24 horas. Este extrato foi diluído a 50, 25, 12,5 e 6,25\% no meio de Eagle. Após incubação de uma suspensão da linhagem celular NCTC clone $929\left(2,5 \times 10^{5}\right.$ céls $\left./ \mathrm{mL}\right) \mathrm{em}$ microplacas de 96 poços de fundo chato, por $24 \mathrm{~h}$ a $37^{\circ} \mathrm{C}$ em atmosfera contendo $5 \%$ de $\mathrm{CO}_{2}$ foi adicionado, a cada poço, volume de $0,2 \mathrm{~mL}$ dos extratos e suas diluições, assim como os controles positivo e negativo, respectivamente extrato de fragmentos de látex $(0,1 \mathrm{~g}$ de látex $/ \mathrm{mL}$ de meio de Eagle e extrato de papel de filtro atóxico $\left(4 \mathrm{~cm}^{2} / \mathrm{mL}\right)$. Após incubação nas mesmas condições, o meio contendo as amostras foi desprezado e substituído por meio de Eagle sem soro contendo $50 \mu \mathrm{g} / \mathrm{mL}$ de vermelho neutro, incubando-se novamente as microplacas. Após 3 horas de incubação, o meio de cultura foi removido e as células lavadas duas vezes com $0,2 \mathrm{~mL}$ de solução fosfatada tamponada, em seguida com $0,2 \mathrm{~mL}$ de solução aquosa de formaldeído $40 \%$ contendo $1 \%$ de $\mathrm{CaCl}_{2}$, para remover o corante não incorporado. Uma solução aquosa de ácido acético $1 \%$ em etanol $50 \%$ foi adicionada para extrair o corante incorporado. Após 10 minutos de agitação as placas foram levadas para leitura da densidade óptica num leitor de microplacas (Organon Teknika Reader 530) equipado com filtro de $540 \mathrm{~nm}$. O extrato do controle positivo foi diluído na proporção de 2:1, sendo esta diluição empregada no preparo das concentrações de trabalho. Os controles foram avaliados nas concentrações de $100,50,25,12,5$ e $6,25 \%$. Para o controle de células foi empregado o meio de Eagle com 5\% de soro fetal bovino. A viabilidade celular foi determinada pela razão entre a densidade óptica de cada diluição e a densidade óptica do controle de células.

\section{RESULTADOS E DISCUSSÃO}

Os valores da biocarga dos implantes de silicone de superfície lisa e texturizada (Tabela I), embora não tenham sido utilizados na determinação dos parâmetros dos processos de esterilização empregados, são cruciais para a eficácia da esterilização, uma vez que, para uma população microbiana exposta a um processo letal, a perda da viabilidade ocorre de maneira regular, ou seja, uma proporção constante da população sobrevivente é inativada a cada incremento de exposição ao agente letal e sendo esta carga microbiana baixa, há maior probabilidade de se atingir a condição de esterilidade (Lambert, 2003).

Além da quantificação da biocarga, a identificação dos microrganismos permite determinar a origem da contaminação (pessoal, insumos, processo produtivo). Os microrganismos isolados das amostras dos implantes (Tabela II) caracterizam-se por serem oriundos, em sua maioria, da microbiota humana, indicando contaminação pelo pessoal. A presença do Bacillus cereus, comumente encontrado no solo e na vegetação, indica contaminação por poeira (Koneman et al., 2001; Hugo, 1990).

A realização do teste de esterilidade das amostras submetidas aos processos de esterilização (calor seco e óxido de etileno) resultou em ausência de crescimento microbiano (Tabela III), comprovando, assim, a eficácia dos processos de esterilização. Apesar de processo convencionalmente utilizado, a condição atípica da esterilização empregada para o calor seco $\left(121^{\circ} \mathrm{C}\right)$, temperatura usualmente empregada para autoclavação, visou minimizar os riscos de toxicidade. Contudo houve necessidade de exposição por período de tempo mais longo (32 h).

TABELA III - Resultados do teste de esterilidade realizado com as amostras de implantes esterilizadas por calor seco e óxido de etileno

\begin{tabular}{lccccc}
\hline \multirow{2}{*}{ Implante de silicone } & \multicolumn{2}{c}{ Calor Seco } & & \multicolumn{2}{c}{ Óxido de Etileno } \\
\cline { 2 - 3 } \cline { 5 - 6 } & $\begin{array}{c}\text { caldo caseína } \\
\text { de soja }\end{array}$ & $\begin{array}{c}\text { caldo } \\
\text { Tioglicolato }\end{array}$ & & $\begin{array}{c}\text { caldo caseína } \\
\text { de soja }\end{array}$ & $\begin{array}{c}\text { caldo } \\
\text { tioglicolato }\end{array}$ \\
\hline Superfície lisa & $0 / 100$ & $0 / 100$ & & $0 / 100$ & $0 / 100$ \\
Superfície texturizada & $0 / 100$ & $0 / 100$ & & $0 / 100$ & $0 / 100$ \\
\hline
\end{tabular}


TABELA IV - Valor médio da viabilidade celular (\%) dos extratos das amostras de implantes de silicone esterilizados por calor seco

\begin{tabular}{cccccc}
\hline Concentração & \multicolumn{2}{c}{ Implantes de silicone } & & \multicolumn{2}{c}{ Controles } \\
\cline { 2 - 3 } \cline { 5 - 6 } dos extratos(\%) & superfície lisa & superfície texturizada & & negativo & positivo \\
\hline 100 & 75 & 84 & 60 & 3 \\
50 & 100 & 104 & 124 & 2 \\
25 & 113 & 113 & 118 & 2 \\
12,5 & 115 & 122 & 98 & 83 \\
6,25 & 125 & & 92 & 82 \\
\hline
\end{tabular}

TABELA V - Valor médio da viabilidade celular (\%) dos extratos das amostras de implantes de silicone esterilizados por óxido de etileno

\begin{tabular}{cccccc}
\hline Concentração & \multicolumn{2}{c}{ Implantes de silicone } & & \multicolumn{2}{c}{ Controles } \\
\cline { 2 - 3 } \cline { 5 - 6 } dos extratos(\%) & superfície lisa & superfície texturizada & & negativo & positivo \\
\hline 100 & 86 & 82 & 119 & 3 \\
50 & 130 & 123 & & 127 & 2 \\
25 & 137 & 147 & 148 & 3 \\
12,5 & 136 & 142 & & 161 & 108 \\
6,25 & 109 & & 78 & 106 \\
\hline
\end{tabular}

A comprovação da biocompatibilidade dos implantes de silicone após serem submetidos à esterilização visa atender ao exigido por normas internacionais (ISO 10993-1:1997, ISO 14607:2002). Inúmeros métodos in vitro têm sido empregados na avaliação da biocompatibilidade de biomateriais (Wodtke et al., 2003; Ignatius, Claes, 1996), sendo o método de captura do vermelho neutro empregado tanto na avaliação da biocompatibilidade de correlatos (Montanaro et al., 2001; Pariente, Kim, Atala, 2001) como também na avaliação de produtos cosméticos e suas matérias-primas (Lee et al., 2000; Jones et al., 2003). O uso deste método in vitro devese à sua sensibilidade e reprodutibilidade (Cruz, 2003), comparativamente aos métodos in vivo, aliado à tendência da substituição do uso de animais (Eisenbrand et al., 2002). Neste método, ao se determinar a viabilidade celular para diferentes concentrações dos extratos obtidos com as amostras é possível o cálculo do $\mathrm{IC}_{50}$, ou seja, a concentração que provoca a perda de $50 \%$ da viabilidade celular, sendo que neste estudo, este cálculo não foi possível pois para todas as concentrações avaliadas, a viabilidade celular foi superior a $50 \%$ (Tabelas IV e V).

\section{CONCLUSÕES}

O alto índice de viabilidade apresentado pelas células expostas aos extratos das amostras de implantes de silicone demonstra o não comprometimento da biocompatibilidade dos implantes de silicone, após terem sido submetidos aos processos esterilizantes por calor seco e óxido de etileno, garantindo o atendimento às normas internacionais bem como a segurança biológica das próteses mamárias como biomateriais implantáveis.

\section{ABSTRACT}

\section{Biocompatibility assessment of silicone gel breast} implants sterilized by dry-heat and by ethylene oxide

Silicone breast implants have been widely used for mammary augmentation and reconstruction surgery. Biological safety of these implants can be altered by sterilization methods. This study consisted of the biocompatibility assessment of smooth and textured silicone gel breast implants sterilized by dry-heat and ethylene oxide through cell viability, employing neutral red uptake method. The NCTC clone 929 cell were employed and the results showed no cytotoxicity of implants after both sterilization processes.

UNITERMS: Breast implants. Silicone. Biocompatibility. Sterilization. Neutral red uptake. Ethylene oxide. Dryheat. 


\section{REFERÊNCIAS BIBLIOGRÁFICAS}

BORENFREUND, E.; PUERNER, J.A. Toxicity determined in vitro by morphological alterations and neutral red absorption. Toxicol. Lett., Amsterdam, v.24, p.119-124, 1985.

CRUZ, A.S. Teste de citotoxicidade in vitro como alternativa ao teste in vivo de Draize na avaliação de produtos cosméticos. São Paulo, 2003. 107. [Tese de Doutorado - Faculdade de Ciências Farmacêuticas da USP].

EISENBRAND, G.; POOL-ZOBEL, B.; BAKER, V.; BALLS, M.; BLAAUBOER, B.J.; BOOBIS, A.; CARERE, A.; KEVEKORDES, S.; LHUGUENOT, J.C.; PIETERS, R.; KLEINER, J. Methods of in vitro toxicology. Food Chem. Toxicol., Oxford, v.40, p.193-236, 2002.

HUGO, W.B. Introduction to microbiology In: DENYER, S.P.; BAIRD, R.M. Guide to microbiological control in pharmaceuticals. London: Ellis Horwood Limited, 1990. cap.1, p.9-28.

IGNATIUS, A.A.; CLAES, L.E. In vitro biocompatibility of bioresorbable polymers: poly (L, DL lactide) and poly (Llactide-glycolide). Biomaterials, Amsterdam, v.17, n.8, p.831-839, 1996.

INTERNATIONAL ORGANIZATION FOR STANDARDIZATION. ISO 11135: medical devices: validation and routine control of ethylene oxide sterilization. Geneva: ISO, 1994. 24p.

INTERNATIONAL ORGANIZATION FOR STANDARDIZATION. ISO 10993-1: biological evaluation of medical devices. Part 1 . Guidance on selections tests. Geneve: ISO, 1997. 10p.

INTERNATIONAL ORGANIZATION FOR STANDARDIZATION. ISO 14607: implants for surgery: specific requirements for mammary implants. Geneva: ISO, 2002. 16p.

JONES, P.A.; KING, A.V.; EARL, E.K.; LAWRENCE, R.S. An assessment of the phototoxic hazard of a personal product ingredient using in vitro assays. Toxicol. In Vitro, Oxford, v.17, p.471-480, 2003.
KONEMAN, E.W.; ALLEN, S.D.; JANDA, W.M.; SCHRECKENBERGER, P.C.; WINN Jr, W.C. Diagnóstico microbiológico: texto e atlas colorido. Rio de Janeiro: MEDSI, 2001. 1465p.

LAMBERT, R.J.W. A model for the thermal inactivation of microorganisms. J. App. Microbiol., v.95, p.500-507, 2003.

LEE, J.K.; KIM, B.B.; KIM, I.I.; KIM, P.Y. In vitro cytotoxicity tests on cultured human skin fibroblasts to predict skin irritation potencial of surfactants. Toxicol. In Vitro, Oxford, v.14, p.345-349, 2000.

MONTANARO, L.; ARCIOLA, C.R.; CENNI, E.; CIAPETTI, G.; SVIOLI, F.; FILIPPINI, F.; BARSANTI, L.A. Cytotoxicity, blood compatibility and antimicrobial activity of two cyanoacrylate glues for surgical use. Biomaterials, Amsterdam, v.22, p.59-66, 2001.

PARIENTE, J.-1.; KIM, B.-S.; ATALA, A. In vitro biocompatibility assessment of naturally derived and syntetic biomaterials using normal human urothelial cells. J. Biomed. Mat. Res., New York, v.55, p.33-39, 2001.

SEAL, B.L.; OTERO, T.C.; PANITCH, A. Polymeric biomaterials for tissue and organ regeneration. Mater. Sci. Eng., Amsterdam, v.34, n.4/5, p.147-230, 2001.

UNITED States pharmacopeia. 27.ed. Rockville: United States Pharmacopeial Convention, 2004. p.1697-1703.

WILLIAMS, D.F., ed. Biocompatibility of tissue analogs. Boca Raton: CRC Press, 1985. 166p.

WILLIAMS, D.F. Dictionary of biomaterials. Liverpool: Liverpool University Press, 1999. p.42.

WOEDTKE, T.; SCHLÜTER, B.; HARTMANN, V.; URBAN, G.; ABEL, P.U.; WILHELM, L.; JÜLICH, W.F.; SCHLOSSER, M. The influence of sterilization treatments on the cytocompatibility of polyurethane biosensor membranes. In: ANNUAL MEETING AND EXPOSITION, 29, Reno, 2003. Abstracts. Minneapolis: Society for Biomaterials, 2003.

Recebido para publicação em 01 de março de 2005. Aceito para publicação em 25 de maio de 2005. 